\title{
PERBEDAAN DERAJAT KECEMASAN WANITA PERIMENOPAUSE YANG MENGIKUTI YOGA DAN TIDAK MENGIKUTI YOGA
}

\author{
Erina Wahyuni ${ }^{1}$, Vita M. Tarawan' ${ }^{2}$, Tuti Wahmurti A. Sapiie ${ }^{3}$ \\ ${ }^{1}$ Fakultas Kedokteran, Universitas Padjadjaran, Bandung, Indonesia, \\ ${ }^{2}$ Divisi Fisilogi, Fakultas Kedokteran, Universitas Padjadjaran, Bandung, Indonesia, \\ ${ }^{3}$ Departemen Ilmu Kedokteran Jiwa, RSUP Dr. Hasan Sadikin, Bandung, Indonesia.
}

\begin{abstract}
Anxiety is one of clinical manifestations of perimenopausal phase. Managing anxiety is important because excessive anxiety can lower the quality of life of perimenopausal woman. Beside pharmacological treatment, there are some nonpharmacological treatment options which can be used to manage excessive anxiety, one of them is by don yoga. The purpose of this research is to know the difference of anxiety level between perimenopausal women with and without yoga. This research is an analytical observation using cross-sectional method. Research subjects were selected randomly, consisted of 103 perimenopausal women between the ages of $39-51$ which divided into 2 groups, namely perimenopausal women with and without yoga. Data was collected using a self-completion questionnaire and consist of general identity, information about participation in yoga, and Zung's Self-Rating Anxiety Scale to measure the anxiety level. Result shows that on the group of perimenopausal women with yoga, 5 respondents $(9,8 \%)$ are anxious and 46 respondents $(90.2 \%)$ are not anxious. On the group of perimenopausal women without yoga, 16 respondents (30.8\%) are anxious and 36 respondents $(69.2 \%)$ are not anxious. Data analysis shows that there is significant difference in anxiety level between perimenopausal women with and without yoga $(p=0.008)$. Conclusion of the study is the anxiety level of perimenopausal women with yoga is lower than the anxiety level of perimenopausal women without yoga.
\end{abstract}

Keywords: anxiety, with yoga, without yoga

Korespondensi: Redaksi JIFO, Laboratorium Sentral, Universitas Padjadjaran, Jalan Raya Jatinangor KM. 21, Sumedang, Jawa Barat, Indonesia. E-mail: amrosdianto@ gmail.com 


\section{PENDAHULUAN}

Setiap wanita secara alamiah akan mengalami proses menopause. Menopause adalah titik waktu berhentinya menstruasi secara permanen akibat berhentnya aktivitas ovarium. Untuk sampai pada tahap tersebut, seorang wanita harus terlebih dahulu mengalami proses transisi dari fase reproduksi yang ditandai dengan menstruasi ke fase infertile yang ditandaidengan menopause. Fase peralihan dari fase reproduksi menuju fase infertile ini disebabkan oleh adanya penurunan fungsi generatif dari ovarium, dan disebut dengan perimenopause. ${ }^{1}$

Pada fase perimenopause, terjadi deplesi folikel-folikel indung telur secara sekunder karena apoptosis. Akibatnya, terjadi suatu ketidakseimbangan ritme hormonal, yang ditandai dengan penurunan produksi hormon estrogen. Hal ini menyebabkan seorang wanita memiliki risiko tinggi terhadao gejala dan penyakit yang terkait dengan defisiensi hormon estrogen, seperti infertilitasm osteoporosis, penyakit kardiovaskuler, terjadinya gekalagejala vasomotor, dan lain-lain. gejala dan penyakit tersebut seringkali menyebabkan kualitas hidup seorang wanita menurun. Salah satu gejala pada fase perimenopause yang terkait dengan penurunan kualitas hidup wanita adalah terganggunya stabilitas emosi seorang wanita perimenopause akibat ketidakseimbangan hormonal. Keadaan emosi tersebut antara lain adalah kecemasan. ${ }^{2}$

Ansietas (kecemasan) adalah suatu keadaan emosi yang tidak menyenangkan terkait dengan perubahan psikofisiologi sebagai respon terhadap konflik intrapsikis. Kecemasan sebenarnya

\section{METODE}

Penelitian dilakukan di pusat latihan yoga di Bandung dari bulan Juli hingga Desember 2012. Subjek penelitian adalah wanita perimenopause yang mengikuti yoga dan tidak mengikuti yoga, kemudian dibagi ke dalam 2 kelompok berdasarkan partisipasi dalam yoga dan derajat kecemasan. Kriteria inklusi penelitian ini adalah wanita berusia 39-51 merupakan suatu sinyal yang memperingatkan akan adanya ancaman internal atau eksternal. ${ }^{3}$

Kecemasan lebih sering ditemukan pada wanita yang pada tahap tertentu dalam hidupnya mengalami proses-proses fisiologis yang melibatkan perubahan kadar hormon estrogen secara drastis, seperti menstruasi dan menopause. Gangguan cemas dapat terjadi pada wanita perimenopause yang tidak mampu beradaptasi terhadap perubahan-perubahan yang terjadi pada fase perimenopause. ${ }^{4,5}$

Relaksasi merupakan salah satu jenis olahraga yang dapat digunakan untuk mengatasi gangguan cemas. Salah satu jenis relaksasi yang akhir-akhir ini banyak diminati adalah yoga. Yoga adalah suatu teknik meditasi yang merupakan warisan dari budaya India. Yoga terdiri dari gerakan-gerakan yang terkendali dan latihan pernapasan. Latihan yoga telah terbukti dapat menngkatkan derajat kesehatan tubuh dan emosi, karena yoga dapat membantu mengolah pernapasan, gerak, dan konsentrasi. ${ }^{6-8}$

Dalam penelitiannya mengenai efek yoga terhadap kecemasan berdasarkan intervensi pola hidup, Ghupta et al menjelaskan bahwa terdapat perbaikan derajat kecemasan yang bermakna. Ross et al membandingkan yoga dengan berolahraga teratur dalam manfaat kesehatan dan mendapatkan reduksi signifikan dari gejala-gejala psikis, termasuk cemas, setelah mengikuti yoga. ${ }^{4,9}$ Penelitian ini bertujuan untuk mengetahui perbedaan derajat kecemasan antara wanita perimenopause yang mengikuti yoga dan tidak mengikuti yoga.

tahun, perimenopause yang mengikuti maupun tidak mengikuti yoga, serta bersedia mengikuti penelitian. Kriteria eksklusi adalah jika data yang diperoleh tidak lengkap.

Subjek penelitian diminta mengisi kuesioner yang terdiri dari identitas pasien dan informed consent, data keikutsertaan yoga, dan Zung's self-rating anxiety scale 
(ZSAS) untuk mengetahui derajat kecemasan responden.

Data dianalisis menggunakan analisis bivariat. Uji hipotesis komparatif kategorik dua kelompok tidak berpasangan yang dipakai adalah uji Chi-square. Jika uji Chi-square, yaitu sel yang mempunyai

\section{HASIL}

Karakteristik subjek yang mengikuti yoga tertera pada tabel 1. Pada kelompok usia 39-45 tahun, 2 orang mengikuti yoga 0-2 kali per minggu, 5 orang mengikuti yoga 3-5 kali per minggu, dan 6 orang mengikuti yoga lebih dari 5 kali per minggu. Sementara itu, pada kelompok usia 46-51 tahun, 15 orang mengikuti yoga 0-2 kali per minggu 3 orang mengikuti yoga 3-5 kali per minggu, dan tidak ada yang mengikuti yoga lebih dari 5 kali per minggu. Pada kelompok usia 39-45 tahun, 11 orang telah mengikuti yoga selama kurang dari 3 bulan, 4 orang telah mengikuti yoga selama 3-6 bulan, dan 18 orang telah mengikuti yoga selama lebih dari 6 bulan. Pada kelompok usia 4651 tahun, sebanyak 9 orang telah mengikuti yoga selama kurang dari 3 bulan, 4 orang telah mengikuti yoga 3-6 bulan, dan 5 orang telah mengikuti yoga selama lebih dari 6 bulan.

Karakteristik subjek penelitian yang tidak mengikuti yoga dapat dilihat pada tabel 2. Subjek penelitian yang berolahraga $0-2$ kali per minggu sebanyak 22 orang, 3 - 5 kali per minggu sebanyak 25 orang, dan lebih dari 5 kali per minggu sebanayak 5 orang. Sementara itu, 12 orang telah berolahraga kurang dari 3 bulan, 5 orang telah berolahraga $3-6$ bulan, dan 35 orang telah berolahraga lebih dari 6 bulan.

Derajat kecemasan pada subjek penelitian yang mengikuti yoga disajikan dalam tabel 3. Terdapat 5 dari 37 orang yang melakukan yoga $0-2$ kali per minggu mengalami kecemasan dan tidak ada orang yang berolahraga lebih dari 2 kali per minggu yang mengalami kecemasan. Sebanyak 1 dari 20 orang yang mengikuti yoga kurang dari 3 bulan, 1 dari 8 orang yang mengikuti yoga $3-6$ bulan, nilai yang diharapkan kurang dari 5 maksimal 20\% dari jumlah sel, tidak terpenuhi, maka dipakai uji alternatifnya, yaitu uji Fisher. Untuk mempermudah perhitungan, digunakan perangkat lunak program komputer SPSS versi 17.0. ${ }^{10}$

dan 3 dari 23 orang yang mengikuti yoga lebih dari 6 bulan mengalami kecemasan.

Derajat kecemasan pada subjek penelitian yang tidak mengikuti yoga disajikan dalam tabel 4. Terdapat 6 dari 22 orang yang berolahraga $0-2$ kali perminggu, 9 dari 25 orang yang berolahraga 3 - 5 kali perminggu, dan 1 dari 5 orang yang berolahraga lebih dari 5 kali perminggu mengalami kecemasan. Sebanyak 7 dari 12 orang yang telah berolahraga kurang dari 3 bulan, 3 dari 5 orang yang telah berolahraga selama $3-6$ bulan, dan 6 dari 35 orang yang telah berolahraga lebih dari 6 bulan mengalami kecemasan.

Berdasarkan tabel 3 dan 4, dapat diketahui bahwa pada kelompok subjek penelitian yang mengikuti yoga, sebanyak 5 orang (4.9\%) mengalami gangguan cemas dan 46 orang $(44,7 \%)$ tidak mengalami gangguan cemas. Pada kelompok subjek yang tidak mengikuti yoga, 16 orang $(15,5 \%)$ mengalami gangguan cemas dan 36 orang $(35 \%)$ tidak mengalami gangguan cemas.

Perbandingan skor kecemasan antara wanita perimenopause yang mengikuti yoga dan yang tidak mengikuti yoga disajikan dalam tabel 5 . Perbandingan nilai median menunjukkan bahwa derajat kecemasan pada kelompok wanita perimenopause yang mengikuti yoga kebih kecil daripada yang tidak mengikuti yoga (29 vs 32,5). Nilai rerata skor kecemasan wanita perimenopause yang mengikuti yoga lebih kecil daripada yang tidak mengikuti yoga $(28,73$ vs 33,4$)$.

Setelah dilakukan uji perhitungan Chi-square, terdapat perbedaan yang bermakna dari derajat kecemasan antara wanita perimenopause yang mengikuti yoga dan tidak mengikuti yoga. 
Tabel 1. Karakteristik subjek penelitian yang mengikuti yoga berdasarkan usia, frekuensi, dan lama mengikuti yoga

\begin{tabular}{|c|c|c|c|c|}
\hline & & \multicolumn{2}{|c|}{ Usia } & \multirow[b]{2}{*}{$\begin{array}{r}\text { Total } \\
(\mathbf{n}=\mathbf{5 1})\end{array}$} \\
\hline & & $\begin{array}{l}39-45 \\
(n=33)\end{array}$ & $\begin{array}{l}46-51 \\
(n=18)\end{array}$ & \\
\hline \multirow{3}{*}{$\begin{array}{l}\text { Frekuensi } \\
\text { (perminggu) }\end{array}$} & $0-2$ & 22 & 15 & 37 \\
\hline & $3-5$ & 5 & 3 & 8 \\
\hline & $>5$ & 6 & 0 & 6 \\
\hline \multirow{3}{*}{$\begin{array}{l}\text { Lama } \\
\text { mengikuti } \\
\text { yoga (bulan) }\end{array}$} & $<3$ & 11 & 9 & 20 \\
\hline & $3-6$ & 4 & 4 & 8 \\
\hline & $>6$ & 18 & 5 & 23 \\
\hline
\end{tabular}

Tabel 2. Karakteristik subjek penelitian yang tidak mengikuti yoga berdasarkan usia, frekuensi olahraga, dan lama mengikuti olahraga.

\begin{tabular}{|c|c|c|c|c|}
\hline & & \multicolumn{2}{|c|}{ Usia } & \multirow{2}{*}{$\begin{array}{r}\text { Total } \\
(n=52)\end{array}$} \\
\hline & & $\begin{array}{l}39-45 \\
(n=21)\end{array}$ & $\begin{array}{l}46-51 \\
(n=31)\end{array}$ & \\
\hline \multirow{3}{*}{$\begin{array}{l}\text { Frekuensi } \\
\text { (perminggu) }\end{array}$} & $0-2$ & 9 & 13 & 22 \\
\hline & $3-5$ & 9 & 16 & 25 \\
\hline & $>5$ & 3 & 2 & 5 \\
\hline \multirow{3}{*}{$\begin{array}{l}\text { Lama } \\
\text { mengikuti } \\
\text { olahraga } \\
\text { (bulan) }\end{array}$} & $<3$ & 7 & 5 & 12 \\
\hline & $3-6$ & 1 & 4 & 5 \\
\hline & $>6$ & 13 & 22 & 35 \\
\hline
\end{tabular}

Tabel 3. Karakteristik subjek penelitian yang mengikuti yoga berdasarkan derajat kecemasan.

\begin{tabular}{lcccc}
\hline & & \multicolumn{2}{c}{$\begin{array}{c}\text { Derajat } \\
\text { Kecemasan }\end{array}$} & Total \\
\cline { 2 - 4 } & & $\begin{array}{c}\text { Cem } \\
\text { as } \\
(\mathbf{n = 5})\end{array}$ & $\begin{array}{c}\text { Tidak } \\
\text { Cemas } \\
(\mathbf{n = 4 6})\end{array}$ & \\
\hline Frekuens) & & \\
\hline (perminggu) & $3-5$ & 0 & 8 & 37 \\
\hline Lama & $>5$ & 0 & 6 & 8 \\
mengikuti & $3-6$ & 1 & 7 & 6 \\
yoga (bulan) & $>6$ & 3 & 20 & 8 \\
\hline
\end{tabular}

Tabel 4. Karakteristik subjek penelitian yang tidak mengikuti yoga berdasarkan derajat kecemasan

\begin{tabular}{lcccc}
\hline & & \multicolumn{2}{c}{ Derajat Kecemasan } & Total \\
\cline { 3 - 4 } & & $\begin{array}{c}\text { Cemas } \\
(\mathbf{n = 1 6})\end{array}$ & $\begin{array}{c}\text { Tidak Cemas } \\
(\mathbf{n = 3 6})\end{array}$ & $\begin{array}{c}\text { (n=52) } \\
\text { Frekuensi }\end{array}$ \\
$\begin{array}{lcccc}\text { (perminggu) } \\
\text { Lama mengikuti }\end{array}$ & $3-5$ & 6 & 16 & 22 \\
olahraga (bulan) & $3-6$ & 3 & 16 & 25 \\
& $>6$ & 6 & 4 & 5 \\
\hline
\end{tabular}


Tabel 5. Perbandingan skor kecemasan wanita perimenopause yang mengikuti yoga dan tidak mengikuti yoga

\begin{tabular}{lcccc}
\hline & $\overline{\mathrm{x}}_{ \pm}$SD & Median & Minimum & Maksimum \\
\hline Yoga & $28,73 \pm 5,73$ & 29,00 & 20,00 & 46,00 \\
Tidak Yoga & $33,4 \pm 5,21$ & 32,50 & 24,00 & 49,00
\end{tabular}

\section{DISKUSI}

Hasil penelitian menunjukkan bahwa terdapat perbedaan derajat kecemasan wanita perimenopause yang mengikuti yoga dan tidak mengikuti yoga berdasarkan hasil pemeriksaan menggunakan Zung's self rating anziety scale (ZSAS) dan uji analisis Chi-square.

Yoga dikatakan memiliki efek langsung dalam menutunkan aktivitas aksis hypothalamus-pituitary-adrenal (HPA) dan sistem saraf simpatis yang distimulasi sebagai respon dari adanya stresor. Aktivasi aksis HPA dan sistem saraf simpatis akan menyebabkan adanya suatu rangkaian efek fisiologis, tingkah laku, dan psikologis yang utamanya merupakan akibat meningkatnya pelepasan hormon kortisol dan katekolamin. Dengan berlatih yoga, terjadi pergeseran dominasi aktivitas sistem saraf dari dominasi sistem saraf simpatis menjadi sistem saraf parasimpatis. Sleain itu, yoga juga dapat menurunkan kadar hormon kortisol dan katekolamin, menurunkan denyut nadi, dan menurunkan tekanan darah. melalui mekanisme inilah penurunan derajat kecemasan dapat terjadi sebagai salah satu keuntungan berlatih yoga. Penelitian menunjukkan bahwa yoga juga dapat memutarbalikkan dampak negatif dari stress terhadap sistem imun dengan cara meningkatkan kadar imunoglobulin A dan sel natural killer (NK), serta menurunkan respons inflamasi. ${ }^{9}$

Berdasarkan penelitian oleh Khalsa mengenai yoga sebagai intervensi terapi, didapatkan bahwa terapat tiga tipe kelainan yang paling sering dievaluasi pada penelitian tentang yoga, yaitu kondisi psikiatri, kelainan kardiovaskular, dan kelainan respirasi. Dari ketiga tipe penyakit tersebut, yang paling banyak mendapat perhatian adalah gangguan cemas. ${ }^{11} \quad$ Ghupta et al melalui penelitiannya tentang efek yoga berdasarkan intervensi pola hidup terhadap kecemasan menjelaskan bahwa terdapat perbaikan yang bermakna dari derajat kecemasan. ${ }^{4}$ Penelitian oleh Ross et al yang membandingkan keuntungan kesehatan dari yoga dan berolahraga teratur melaporkan bahwa baik yoga maupun olahraga teratur menunjukkan reduksi yang signifikan dari gejala-gejala psikis, namun kelompok subjek ynag mengikuti yoga mengalami perbaikan yang lebih signifikan. Yoga juga dikatakan dapat mengurangi kejadian gejolak panas (hot flushes) pada wanita menopause. ${ }^{9}$

Semua penelitian di atas mendukung hasil penelitian ini, yaitu derajat kecemasan antara wanita perimenopause yang mengikuti yoga lebih rendah secara signifikan dibandingkan dengan yang tidak mengikuti yoga,

Keterbatasan pada penelitian ini adalah bahwa kecemasan dipengaruhi oleh berbagai faktor, termasuk di antaranya jenis kelamin, usia, faktor sosial dan etnis, faktor keluarga dan genetik, faktor personal, serta adanya kejadian dalam hidup yang membuat stres (stressful life events). ${ }^{5}$ Selain banyaknya faktor yang memengaruhi kecemasan, hal lain yang perlu diperhatikan adalah luasnya tipe yoga yang dapat dilakukan, sehingga tidak terdapat suatu bentuk praktik yoga yang tentu dan terstandarisasi. ${ }^{11}$ 


\section{KESIMPULAN}

Kesimpulan dari penelitian ini adalah derajat kecemasan wanita perimenopause yang mengikuti yoga lebih

\section{PENDANAAN}

Penelitian ini tidak didanai oleh sumber hibah manapun.

\section{KONFLIK KEPENTINGAN}

Tidak terdapat konflik kepentingan. rendah dibandingkan derajat kecemasan wanita perimenopause yang tidak mengikuti yoga.

\section{DAFTAR PUSTAKA}

1. Baziad A. Menopause \& andropause. Jakarta: Yayasan Bina Pustaka Sarwono Prawirohardjo; 2003.

2. Berek JS. Berek \& Novak's gynecology: Lippincott Williams \& Wuilkins; 2006.

3. Kaplan HI. Sadock BJ. Comprehensive glossary of psychiatry \& psychology: Williams \& Wilkins; 1991.

4. Gupta N, Vempati SKRP, Charma R, Bijlani RL. Effect of yoga based lifestyle intervention on state and trait anxiety. Indian J Physiol Pharmacol. 2006:41-7.

5. Sadock BJ. Sadock VA. Comprehensive textbook of psychiatry: Lippincott Williams and Wilkins; 2007.

2001.

7. Ashton D, Davies B. Why exercise? New York: Basil Blackwell Inc; 1986.

8. Wong MF. Acu yoga: Penebar Plus; 2011.

9. Ross A, Thomas S. Health benefits of yoga and exercise: A review of comparison studies. The Journal of Alternative and Complementary Medicine. 2010;16:3-12.

10. Tarawan VM. Hubungan estradiol, interleukin 6, dan insulin-like growth factor I dengan densitas tulang pada wanita menopause yang berolahraga teratur dan tidak berolahraga teratur. Bandung: Universitas Padjadjaran; 2009.

11. Payne R. Relaxation technique. London: Harcout Publishers Limited; 2000. 